\title{
HEMORRHAGIC SHOCK DUE TO SPONTANEOUS RUPTURE OF ADRENAL PHEOCHROMOCYTOMA
}

\author{
JOSÉ A. BITTENCOURT, MÁRCIO A. AVERBECK, HERBERT J. SCHMITZ \\ Division of General Surgery, Nossa Senhora da Conceição Hospital, Porto Alegre, Rio \\ Grande do Sul, Brazil
}

\begin{abstract}
The spontaneous rupture of an adrenal pheochromocytoma is an extremely rare event; however, it is potentially fatal. We report a case of spontaneous rupture of pheochromocytoma followed by an extensive retroperitoneal hematoma and hypovolemic shock. The correct diagnostic assessment determined the adequate surgical approach and a favorable outcome for the patient.
\end{abstract}

Key words: adrenal glands; pheochromocytoma; rupture; hemorrhage shock

Int Braz J Urol. 2003; 29: 428-30

\section{INTRODUCTION}

The spontaneous rupture of an adrenal pheochromocytoma is an extremely rare event. However, occasionally, the initial manifestation of a pheochromocytoma can be hypotension or even shock due to massive hemorrhage (1). The retroperitoneal hematoma secondary to pheochromocytoma determines its high lethality. We report a case of spontaneous rupture of pheochromocytoma followed by an extensive retroperitoneal hematoma and hypovolemic shock.

\section{CASE REPORT}

Caucasian, 42-year old man, came to the hospital emergency room presenting pain in upper abdomen, of sudden onset, irradiating to left flank, accompanied by nausea and vomiting. Previously healthy, at the moment of admission he presented rigid abdomen that was painful on palpation, mainly in left hypochondrium, without signs of peritoneal irritation. His blood pressure oscillated between $180 \times 100$ and $230 \times 150 \mathrm{mmHg}$, refractory to clinical treatment.
Laboratory tests showed anemia (hemoglobin $=7.5$ $\mathrm{g} / \mathrm{dL}$ ) and leukocytosis (total leukocytes $=21800 / \mu \mathrm{l}$, nonfilament polymorphonuclear leukocytes $=12 \%$ ). The research for vanillylmandelic acid (VMA) in urine was inconclusive (urinary VMA $=7.8 \mathrm{mg} / 24$ hours). The abdominal x-ray made upon admission revealed opacification in left hypochondrium. Computerized tomography showed a left adrenal tumor measuring approximately $5 \mathrm{x} 4 \mathrm{~cm}$ (Figure-1A). It also evidenced left megaureter with hydronephrosis and an extensive retroperitoneal hematoma to the left (Figure-1B). The arteriography performed on the next day demonstrated pathological circulation in left adrenal gland (Figure-2). Patient evolved with hemorrhagic shock within 6 days from his admission to the hospital, and was then submitted to exploratory laparotomy.

Following the incision, a significant amount of free blood was observed in the abdominal cavity. The retroperitonium contained an extensive hematoma and a large left adrenal tumor adhered to the kidney. Left nephrectomy with adrenalectomy was performed. Patient presented a good post-operative outcome, being released from the hospital on the $21^{\text {st }}$ 

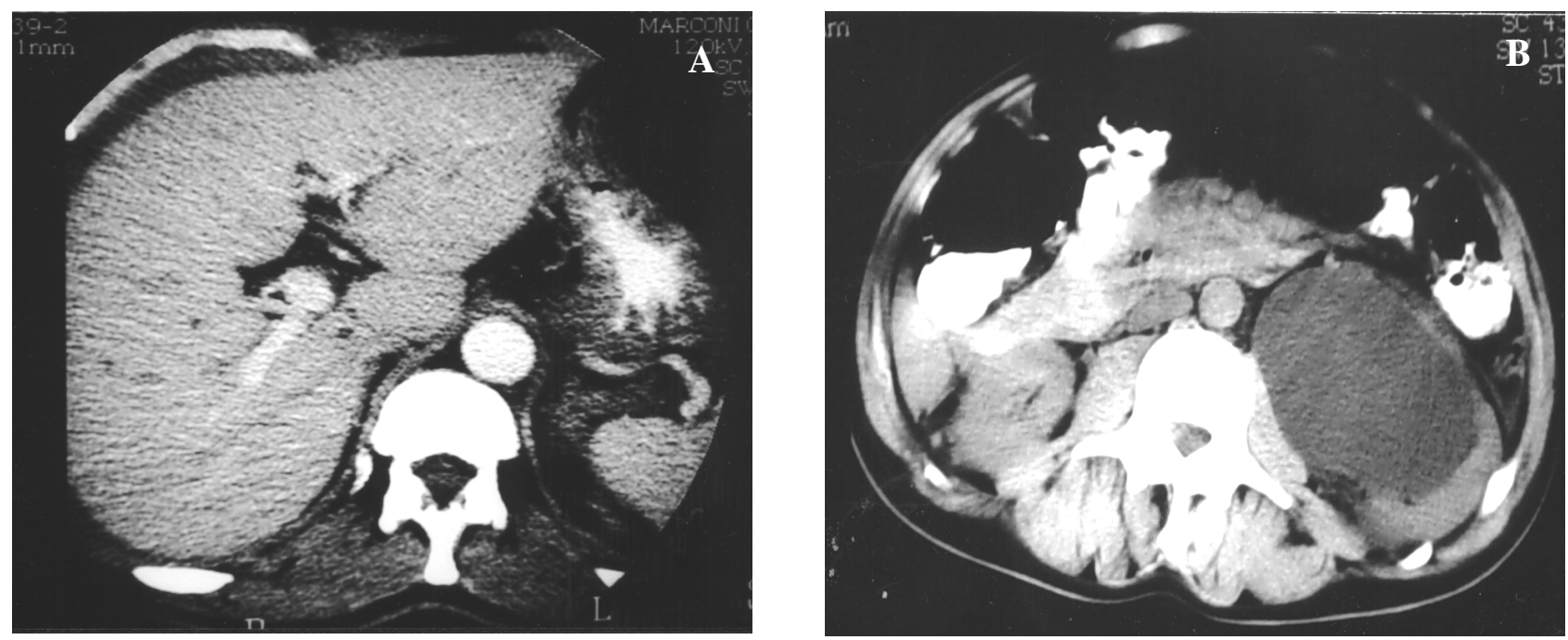

Figure 1 - Computerized tomography of abdomen. A) - Tumor in left adrenal measuring approximately $5 \times 4 \mathrm{~cm}$. B) - Extensive retroperitoneal hematoma on the left.

post-operative day. The pathological examination demonstrated pheochromocytoma

\section{DISCUSSION}

Most patients with spontaneous rupture of pheochromocytoma are admitted to the hospital due to acute abdominal pain. Some present arterial hypertension and peripheral vasoconstriction (2); rarely, as in the case of this patient, they can evolve with hypovolemic shock.

Tanaka et al. reviewed 15 cases of rupture of pheochromocytoma, verifying 4 deaths due to pulmonary edema during or following emergency surgery (2). Among the reported cases, 3 were correctly diagnosed in the pre-operative period and elective surgery was successful following conservative therapy. Such reports suggest that the elective surgery following pharmacological management has a low mortality rate, while emergency surgery in patients without a definitive diagnosis is associated with a high mortality rate $(2,3)$.

The accurate diagnosis is an important aspect in the management of retroperitoneal hematoma resulting from rupture of adrenal pheochromocytoma. Clinical history constitutes important information, since silent pheochromocytoma, such as the one de- scribed in this report, is extremely rare. In this case, computerized tomography and arteriography provided significant subsides to surgical management.

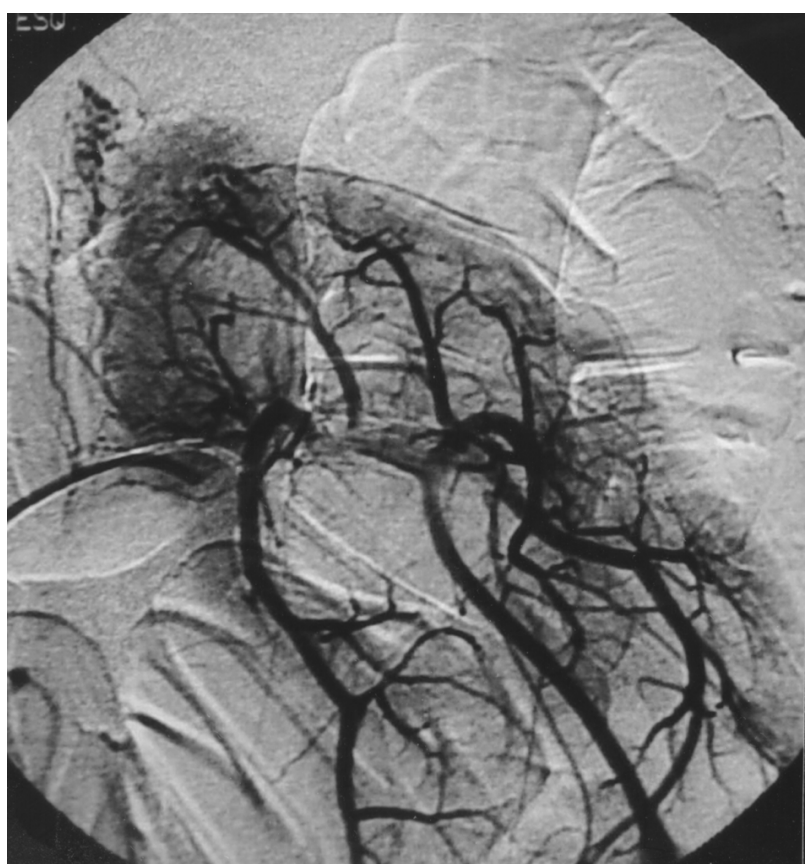

Figure 2 - Arteriography showing pathological circulation in left adrenal gland. 


\section{REFERENCES}

1. Mohamed HA, Aldakar MO, Habib N: Cardiogenic shock due to acute hemorrhagic necrosis of a pheochromocytoma: a case report and review of the literature. Can J Cardiol. 2003; 19: 573-6.

2. Tanaka K, Noguchi S, Shuin T, Kinoshita Y, Kubota
Y, Hosaka M: Spontaneous rupture of adrenal pheochromocytoma: a case report. J Urol. 1994; 151: 1201 .

3. Sumino Y, Tasaki Y, Satoh F, Mimata H, Nomura Y: Spontaneous rupture of adrenal pheochromocytoma. J Urol. 2002; 168: 188-9.

Received: April 4, 2003 Accepted after revision: July 28, 2003

\section{Correspondence address:}

Dr. Márcio Augusto Averbeck

Rua Carlos Silveira Martins Pacheco, 55 / 604 G

Porto Alegre, RS, 91350-300, Brazil

Fax: + 5551 3343-6055

E-mail: marcioaverbeck@ hotmail.com

\section{EDITORIAL COMMENT}

This interesting case report carries an important message; despite several similar cases described, pheochromocytoma with hemorrhagic necrosis and spontaneous rupture with acute abdomen symptoms and shock is an extremely rare condition, however, it must always be considered, in order to avoid a delay in diagnosis and the possibility of progression to death. A brief review of the literature reveals at least 29 cases described up to 1998 . In the majority of cases the bleeding occurs to the retroperitonium, however some may bleed both to the retroperitonium and to the peritoneal cavity, such as in the present case. There has been a trend to maintain the patients clinically stable and to postpone laparotomy to another moment, as soon as they get better, if the case is favorable. The review of literature shows very young patients, such as 16 years old, and a case where this condition was not suspected and the diagnosis was made upon necropsy. Computerized tomography seems to be the best imaging method, especially in clinically silent cases, that present in the emergency room as abdominal pain.

\author{
Dr. Cálide Soares Gomes \\ Service of Urology \\ Federal University of Maranhão \\ São Luís, MA, Brazil
}

